\title{
A Prospective Study of Distal Metatarsal Chevron Osteotomies with K-Wire Fixations to Treat Hallux Valgus Deformities
}

\author{
MN Baig ${ }^{1}$, Muhammad Usman Baig ${ }^{2}$, Ali Tariq $^{3}$, Robert Din ${ }^{4}$
}

1. Orthopaedics, University Hospital Galway, Galway, IRL 2. Internal Medicine, Bahawal Victoria Hospital, Quaid-E-Azam Medical College, Bahawalpur, PAK 3. Trauma \& Orthopaedics, Galway University Hospital , Galway, IRL 4. Department of Orthopaedics, Poole Hospital, Poole, United Kingdom

$\square$ Corresponding author: MN Baig, nouman142@gmail.com

Disclosures can be found in Additional Information at the end of the article

\section{Abstract}

\section{Introduction}

Hallux valgus is one of the most common forefoot deformities worldwide. Females are affected more often than males. The three most common clinical symptoms are the painful bunion, transfer metatarsalgia, and hammer or claw toes.

\section{Methods}

This case series consisted of 20 patients who had chevron osteotomy from January 2015 to January 2016. The clinical assessment was measured by The American Orthopedic Foot and Ankle Score (AOFAS), and radiologic assessment was determined by preoperative and postoperative hallux valgus angle (HVA) and intermetatarsal angle (IMA).

\section{Results}

The patients' mean age was 56 years. Out of 20 patients, 19 were female, and one was male. The mean AOFAS improved from 51 preoperatively to 82 postoperatively. The HVA improved from $26^{\circ}$ preoperatively to $14^{\circ}$. There were five complications including four Kirschner (K)-wire complications.

\section{Conclusion}

Distal chevron osteotomy is a reliable and time-tested procedure. The K-wire fixation has a relatively high complication rate. We planned to use other methods of fixation and then compared them with K-wires fixation results for future studies.

Received 09/06/2017

Review began 09/14/2017 Review ended 09/16/2017 Published 09/20/2017

(C) Copyright 2017

Baig et al. This is an open access article distributed under the terms of the Creative Commons Attribution License CC-BY 3.0., which permits unrestricted use, distribution, and reproduction in any medium, provided the original author and source are credited.
Categories: Orthopedics

Keywords: chevron osteotomy, k wires

\section{Introduction}

Hallux valgus is a condition characterized by progressive lateral or valgus deviation deformity of the great toe of the metatarsophalangeal (MTP) joint. There is a prominence at the metatarsal head (bunion) and varus deformity of the first metatarsal. Due to progressive deformity development, it is often accompanied by other foot abnormalities, including 


\section{Cureus}

secondary osteoarthritis (OA), hammer toes due to crowding, and inflammation of the adventitious bursa over the first MTP joint [1].

The first mention of hallux valgus in the literature was by German surgeon Carl Hueter in 1870 as abducto-valgus deformity of the big toe [2]. Hallux valgus is the most common pathology of the big toe. It is also called as a bunion in the layman terms. This word bunion derives from the Latin word 'bunio' meaning turnip. The typical manifestation of the hallux valgus deformity is a prominence of medial eminence. Not all these are hallux valgus deformities, however; it can include bursal inflammation, ganglion formation, osteoarthritis or gouty arthritis, or any combination of these.

In a recent study, the prevalence of hallux valgus was $23 \%$ in individuals of 18 to 65 years old, and $35.7 \%$ in individuals over the age 65 years. In the juvenile age group, the prevalence is $7.8 \%$ [2-3]. The prevalence of hallux valgus by gender was $30 \%$ among females and $13 \%$ among males $[2]$.

\section{Materials And Methods}

We performed a prospective study from January 2015 to January 2016. We selected the patients with hallux valgus who underwent distal chevron osteotomy for hallux valgus with Kirschner (K)-wire fixation over that period; the K-wire was chosen as it is cost-effective and technically easier to manipulate. The patients were adults. The surgery was performed by an orthopedic foot and ankle surgeon. There was no randomization or blinding of the patients to this study. The patients' progress was followed for one year with regular visits as outpatients (Figures 1-3).

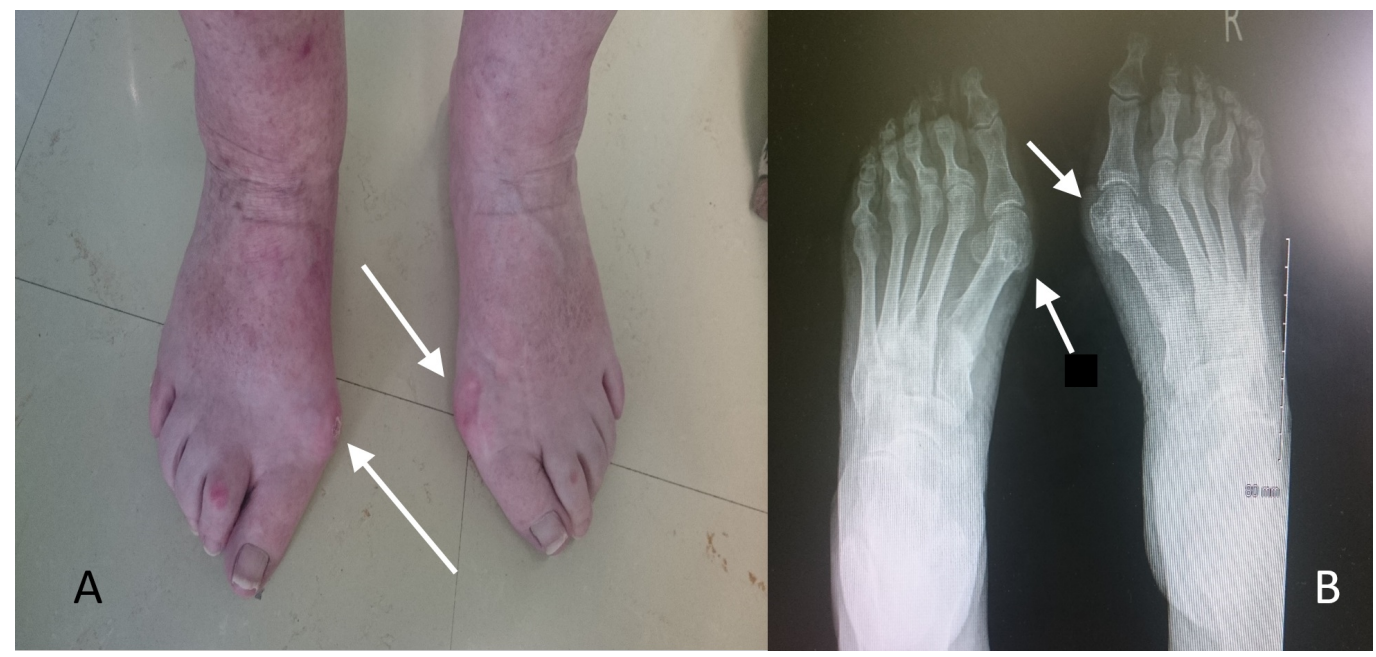

FIGURE 1: The clinical $(A)$ and radiological $(B)$ presentation of a 62-year-old female with hallux valgus deformity.

White arrows showing the clinical and radiological bunion (hallux valgus). 


\section{Cureus}

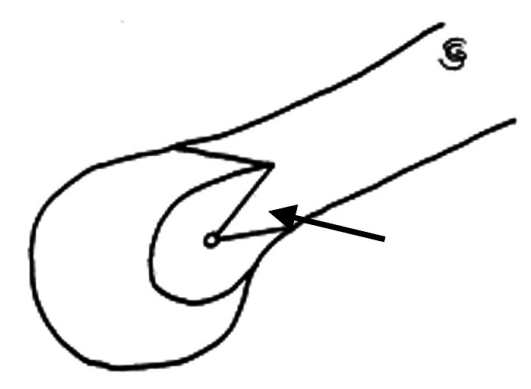

A

FIGURE 2: The distal chevron osteotomy "V" cut (A) and translation (B).

Black arrows showing the cut and translation.

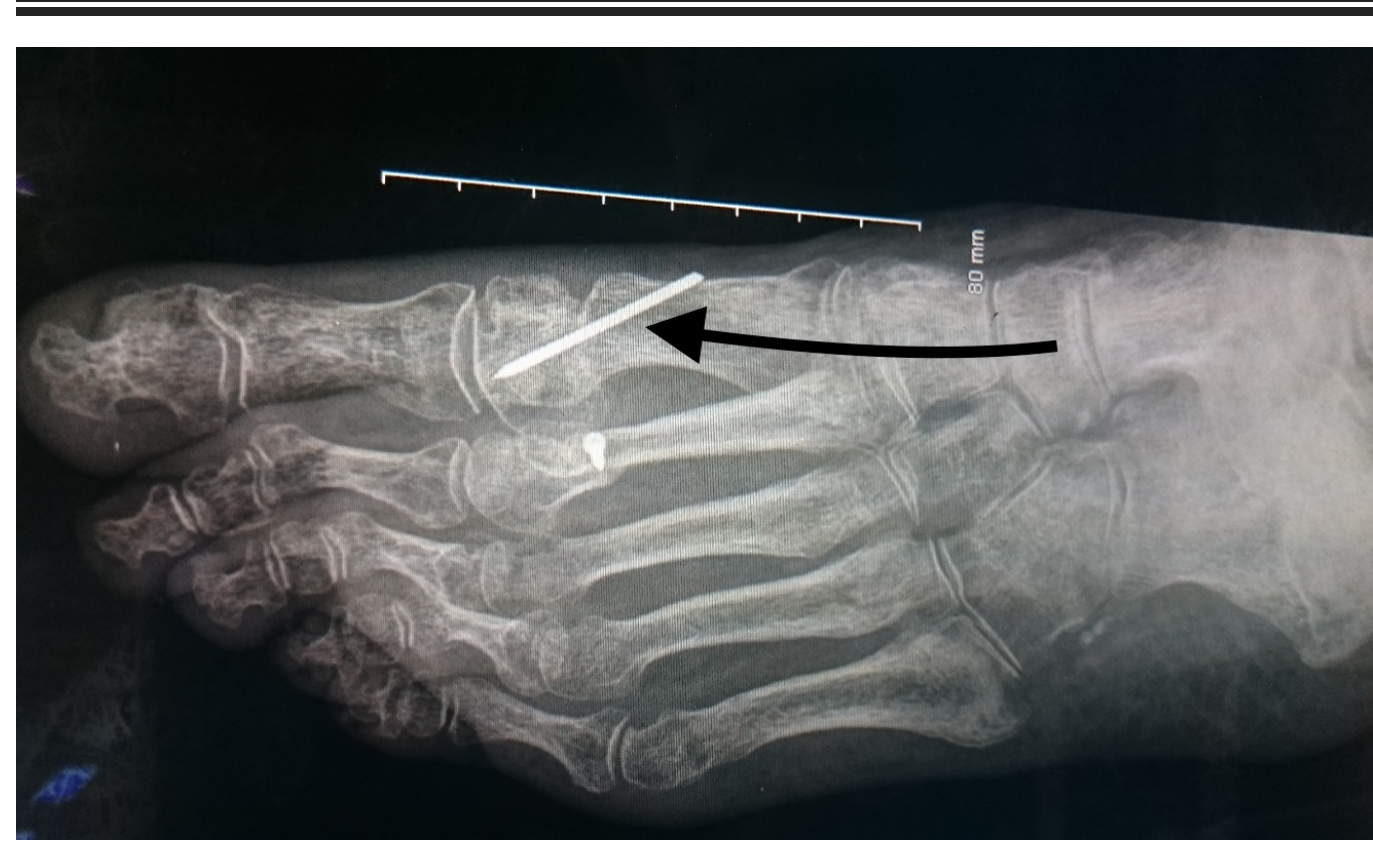

FIGURE 3: The distal chevron osteotomy and Kirschner (K)wire fixation.

Black arrow showing the Kirschner wire fixation of the distal metatarsal chevron osteotomy.

The procedure was performed as a day-care surgery. The patients had a preoperative anesthetic assessment performed a few days prior to the surgery. They were assessed by physiotherapists and occupational therapists and briefed on what to expect post operation regarding mobility and rehabilitation.

The data were collected by the orthopedic team via a specific questionnaire made for this study. Postoperatively, the patients were seen in the outpatient department at an interval of two weeks, six weeks, six months and one year. The patients for the study analysis were selected from the outpatient department. 


\section{Cureus}

\section{Results}

We used Statistical Package for the Social Sciences (SPSS) Statistics for Windows, Version 19.0 (IBM Corp., Armonk, New York) that was released in the year 2010 for statistically analyzing the data collected from the patients. Wilcoxon signed ranked test was used to evaluate the data. The results obtained from this analysis are shown in Table 1.

$$
\mathrm{n}=\mathbf{2 0}
$$

\section{AOFAS}

HV angle (degrees) 26 (20 to 31$)$

IM angle (degrees) 13 (11 to 15)

\section{Preoperative mean (Range)}

$51(38$ to 60$)$

\section{Postoperative one-year follow-up (Range)}

Significance

$82(75$ to 90$)$

$P<.001$

14 (11 to 18$)$

$\mathrm{P}<.001$

$8(6$ to 11$)$

\section{TABLE 1: The American Orthopedic Foot and Ankle Score (AOFAS), hallux valgus (HV) angle and intermetatarsal (IM) angle.}

The patients' age ranged from 28 to 73 years, with a mean age of 56 years. Out of 20 patients who underwent chevron osteotomy and were included in this study, 19 (95\%) were female and one (5\%) was male.

The range of the hallux valgus angle (HVA) at the metatarsophalangeal (MTP) joint preoperatively was $20^{\circ}$ to $31^{\circ}$. The postoperative HVA at the one-year follow-up ranged from $11^{\circ}$ to $18^{\circ}$. The mean improvement of MTP angle was from $26^{\circ}$ to $14^{\circ}(\mathrm{P}<.001)$.

The range of the intermetatarsal angle (IMA) preoperatively was $11^{\circ}$ to $15^{\circ}$. After one year, the range was $6^{\circ}$ to $11^{\circ}$ (mean $\left.=8^{\circ}\right)$. This is a statistically significant improvement $(\mathrm{P}<.001)$.

The American Orthopaedic Foot and Ankle Score's (AOFAS) preoperative range was from 38 to 60 (mean=51). At the one-year follow-up, the range was 75 to 90 with a mean of $82(\mathrm{P}<.001)$.

Postoperatively, complications witnessed included one case of postoperative pain and four Kwire complications. The patient who experienced pain was a female who reported pain at the sixth-month and one-year visit. She is being treated symptomatically with topical analgesic and oral analgesic. Four patients had K-wire complications including pin site infection and Kwire migration. Two patients had a K-wire migration of approximately $1 \mathrm{~cm}$ to $1.5 \mathrm{~cm}$ during the intervals of a two-week visit. The other two patients had superficial pin site infections; these were treated with antibiotics for five days.

\section{Discussion}

There are many different types of osteotomies for the correction of the hallux valgus deformity. There are different osteotomies according to anatomical sites. Distal chevron osteotomy has been considered one of the most successful types of osteotomy as it has demonstrated good results in the medical literature. Though it has better results in comparison to the McBride technique and Wilson osteotomy [4-5], when compared to the Scarf osteotomy in randomized trials by Jeuken, et al. and Deenik, et al., the results were similar in both groups [6-7]. The technique of ' $V$ ' shaped osteotomy and lateral displacement is considered as a big step in the correction of hallux valgus and has been proven effective [8-9]. Table 2 shows different types of 


\section{Cureus}

osteotomies.

\section{Metatarsal}

Basal osteotomy, Chevron osteotomy, Hohmann osteotomy, Hueter osteotomy, Kramer osteotomy, Scarf osteotomy, Ludloff osteotomy.
Metatarsophalangeal joint

Metatarsophalangeal (MTP) joint

arthrodesis, McBride soft tissue

balancing procedure.

\section{Phalanx}

Akin osteotomy,

Keller-Brandes

osteotomy.

\section{TABLE 2: Different hallux valgus correction osteotomies according to the site of correction.}

In this study, the mean improvement in the HVA was from $26^{\circ}$ to $14^{\circ}(\mathrm{P}<.001)$. According to the available literature, Chevron osteotomy has been shown to deliver significant improvement in the HVA. Schneider, et al. showed an improvement in the HVA from the mean of $27.6^{\circ}$ to $14.0^{\circ}$ [9]. Likewise, IMA has also shown a statistically significant improvement from a mean value of $12.90^{\circ}$ preoperatively to $8.45^{\circ}$ postoperatively. The AOFAS significantly improved from 50.70 to 82.4 . The literature has repeatedly shown improvements in the HVA and IMA after chevron osteotomy [10-12]. The chevron ' $\mathrm{V}$ ' osteotomy is a biplane osteotomy with the transverse plane and vertical plane. It is inherently stable in only one plane (vertical plane) and is not stable in the transverse plane. The choice of fixation after an osteotomy is dependent on the surgeon's preference, patient compliance, bone stock, and osteotomy type [12].

Different methods of fixation are used, including K-wire, Herbert-Whipple screw, suture anchors or bio-absorbable fixations like polyglycolide pins, staple fixation and plate fixation [9,11]. All these methods of fixation have been used and their results are discussed in the literature; this discussion is confined to our experience with K-wire fixation. It is a popular method because it is a cheap and simple method [12-13]. It is also very easy to remove during the outpatient visits. We used a 1.6-mm K-wire across the osteotomy sites. The K-wires in our study were taken out during outpatient visits at six weeks.

The complications which are generally attributed to K-wire fixation include pin site infection, proximal displacement, distal displacement, pain, lack of interfragmentary compression, no resistance to parallel movement of the wire, and heat generated during insertion [14-15]. Additionally, K-wires can be prone to infection because one end of the K-wire is out of the skin. In comparison with other methods, some studies from the 1990s and early 2000s demonstrated either positive results and relative benefits with K-wire fixation or that the method was at least of equal efficacy [15-16]. In contrast, there have been a number of studies in the literature illustrating superior results for other methods in comparison to K-wire fixation. In a study by Acevedo, et al., it was shown that regardless of the type of osteotomy, screw fixation was mechanically superior to other methods including K-wire fixation [15].

\section{Conclusions}

This study showed that a distal chevron osteotomy can be used successfully for the correction of hallux valgus deformity. Analysis of the preoperative and postoperative values for the HVA, IMA, and AOFAS show statistically significant improvement in all categories measured, both radiologically and clinically. In line with our clinical experience, the rate of K-wire complications in this study was quite high (20\%). Many of the complications such as displacement and pin site infection are preventable. The limitation of this study was the small number of participants. To improve our practice and reduce the complication rate, our aim 
would be to use other methods of fixation instead of k-wire fixation and study their complication and problems to come up with the result of the most appropriate method of fixation.

\section{Additional Information \\ Disclosures}

Human subjects: Consent was obtained by all participants in this study. Animal subjects: All authors have confirmed that this study did not involve animal subjects or tissue. Conflicts of interest: In compliance with the ICMJE uniform disclosure form, all authors declare the following: Payment/services info: All authors have declared that no financial support was received from any organization for the submitted work. Financial relationships: All authors have declared that they have no financial relationships at present or within the previous three years with any organizations that might have an interest in the submitted work. Other relationships: All authors have declared that there are no other relationships or activities that could appear to have influenced the submitted work.

\section{References}

1. Thomas S, Barrington R: Hallux valgus. Orthop Trauma. 2003, 17:299-307. 10.1016/S02680890(02)00184-6

2. Nix S, Smith M, Vicenzino B: Prevalence of hallux valgus in the general population: a systematic review and meta-analysis. J Foot Ankle Res. 2010, 3:21. 10.1186/1757-1146-3-21

3. Baig MN: A review of epidemiological distribution of different types of fractures in pediatric age. Cureus. 2017, 9:10.7759/cureus.1624

4. Wülker N, Mittag F: The treatment of hallux valgus. Dtsch Arztebl Int. 2012, 109:857-67. 10.3238/arztebl.2012.0857

5. Choi GW, Kim HJ, Kim TS, et al.: Comparison of the modified McBride procedure and the distal chevron osteotomy for mild to moderate hallux valgus. J Foot Ankle Surg. 2016, 55:80811. 10.1053/j.jfas.2016.02.014

6. Jeuken RM, Schotanus MGM, Kort NP, et al.: Long-term follow-up of a randomized controlled trial comparing scarf to chevron osteotomy in hallux valgus correction. Foot Ankle Int. 2016, 37:687-95. 10.1177/1071100716639574

7. Deenik AR, Pilot P, Brandt SE, et al.: Scarf versus chevron osteotomy in hallux valgus: a randomized controlled trial in 96 patients. Foot Ankle Int. 2007, 28:537-41. 10.3113/FAI.2007.0537

8. Steinböck G: Chevron-osteotomy for the treatment of hallux valgus . Foot Ankle Surg. 2003, 9:95-102. 10.1016/S1268-7731(03)00016-X

9. Crosby LA, Bozarth GR: Fixation comparison for chevron osteotomies . Foot Ankle Int. 1998, 19:41-43. 10.1177/107110079801900108

10. Schneider W, Aigner N, Pinggera O, et al.: Chevron osteotomy in hallux valgus. Bone Joint J. 2004, 86:1016-20. 10.1302/0301-620X.86B7.15108

11. Lee $\mathrm{KB}$, Seo CY, Hur CI, et al.: Outcome of proximal chevron osteotomy for hallux valgus with and without transverse Kirschner wire fixation. Foot Ankle Int. 2008, 29:1101-6. 10.3113/FAI.2008.1101

12. Panchbhavi VK: Technique tip: buttress Kirschner wire fixation for distal chevron osteotomy . Foot Ankle Int. 2007, 28:133-4. 10.3113/FAI.2007.0023

13. Baig MN, Moftah M, Deasy J, et al.: Implementation and usefulness of single-access laparoscopic segmental and total colectomy. Colorectal Dis. 2012, 14:1267-75. 10.1111/j.1463-1318.2012.02966.x

14. Baig MN, Curtin W: A simple and easy intramedullary lavage method to prevent embolism during and after reamed long bone nailing. Cureus. 2017, 9:10.7759/cureus.1609

15. Armstrong DG, Pupp GR, Harkless LB: Our fixation with fixation: are screws clinically superior to external wires in distal first metatarsal osteotomies?. J Foot Ankle Surg. 1997, 36:353-355. 10.1016/S1067-2516(97)80035-X

16. Ben-Ad R: Fixation updates for hallux valgus correction . Clin Podiatr Med Surg. 2014, 31:265- 


\section{Cureus}

79. 10.1016/j.cpm.2013.12.008 